\title{
Cr(VI) Removal from Aqueous by Adsorption on Amine-Functionalized Mesoporous Silica Prepared from Silica Fume
}

\author{
Xitong Li, ${ }^{1}$ Caiyun Han, ${ }^{1}$ Wenjie Zhu, ${ }^{1,2}$ Wenhui Ma, ${ }^{2,3,4}$ Yongming Luo, ${ }^{1}$ \\ Yang Zhou, ${ }^{2,3,4}$ Jie $\mathrm{Yu}^{2,3,4}$ and Kuixian $\mathrm{Wei}^{2,3,4}$ \\ ${ }^{1}$ Faculty of Environmental Science and Engineering, Kunming University of Science and Technology, Kunming 650093, China \\ ${ }^{2}$ State Key Laboratory of Complex Nonferrous Metal Resources Cleaning Utilization in Yunnan Province/The National Engineering \\ Laboratory for Vacuum Metallurgy, Kunming University of Science and Technology, Kunming 650093, China \\ ${ }^{3}$ Faculty of Metallurgical and Energy Engineering, Kunming University of Science and Technology, Kunming 650093, China \\ ${ }^{4}$ Key Laboratory of Non-Ferrous Metals Vacuum Metallurgy of Yunnan Province/Engineering Research Center for Silicon Metallurgy \\ and Silicon Materials of Yunnan Provincial Universities, Kunming 650093, China
}

Correspondence should be addressed to Wenjie Zhu; zhuwenjie17@163.com and Wenhui Ma; mwhsilicon@163.com

Received 19 June 2014; Revised 3 August 2014; Accepted 4 August 2014; Published 28 August 2014

Academic Editor: Jean-Luc Blin

Copyright (c) 2014 Xitong Li et al. This is an open access article distributed under the Creative Commons Attribution License, which permits unrestricted use, distribution, and reproduction in any medium, provided the original work is properly cited.

\begin{abstract}
Amino-functionalized mesoporous silica MCM-41 materials have been prepared to develop efficient adsorbents of Cr(VI) in wastewater, using silica fume as silica source. Functionalization with amino groups has been carried out by using grafting method. The materials have been characterized by means of X-ray diffraction (XRD), nitrogen $\left(\mathrm{N}_{2}\right)$ adsorption-desorption, Fourier transform infrared (FTIR) spectroscopy, scanning electron microscopy (SEM), transmission electron microscopy (TEM), and X-ray photoelectron spectroscopy (XPS). Adsorption potential of the material for $\mathrm{Cr}(\mathrm{VI})$ removal from aqueous solution was investigated by varying experimental conditions such as $\mathrm{pH}$, initial metal concentration, and contact time. The equilibrium data were analyzed using the Langmuir and Freundlich isotherm by linear regression analysis, and the results show that the adsorption equilibrium data obeyed the Langmuir model. In addition, the kinetics analysis revealed that the overall adsorption process was successfully fitted with the pseudo-second-order kinetic model.
\end{abstract}

\section{Introduction}

The release of heavy metals from industrial entities into the natural environmental has led to serious pollution problem. Presence of heavy metals in water bodies is of great concern. Elevated levels of heavy metals may have adverse impacts on the environment and pose serious human health risks. Chromium is commonly found in the waste effluents from electroplating, metallurgical, tannery, and textile industry $[1,2]$. In the natural environment $\mathrm{Cr}$ occurs in different oxidation states ranging from II to VI, with $\mathrm{Cr}$ (III) and $\mathrm{Cr}(\mathrm{VI})$ as the most abundant species. $\mathrm{Cr}(\mathrm{III})$ is a required nutrient, whereas $\mathrm{Cr}(\mathrm{VI})$ has toxic effects [3]. $\mathrm{Cr}(\mathrm{VI})$ (i.e., $\mathrm{CrO}_{4}{ }^{2-}$ and $\mathrm{Cr}_{2} \mathrm{O}_{7}{ }^{2-}$ ) is very toxic and is a strictly regulated pollutant. Accidental chromium ingestion causes stomach upsets, ulcers, kidney and liver damages, and even death. Moreover, $\mathrm{Cr}(\mathrm{VI})$ is also mutagenic, carcinogenic, and teratogenic and has been recognized as a priority pollutant $[4,5]$.

A wide variety of techniques to remove heavy metals from water is available such as ion exchange, reverse osmosis and nanofiltration, precipitation, coagulation/coprecipitation, and adsorption [6-8]. This last technique is very popular due to simplicity and low cost. The MCM-41 solids exhibit high specific surface areas, high crystallinity, high thermal stability, uniformity of hexagonal cylindrical pores, narrow pore distribution, and regulated pore diameter from 15 to $100 \AA$. Then, those materials with various chelating agents are increasingly utilized as adsorbents because of the high 
TABLE 1: The contents of silica fume.

\begin{tabular}{lcccccccccc}
\hline Sample & $\mathrm{SiO}_{2}$ & $\mathrm{CO}_{2}$ & $\mathrm{~K}_{2} \mathrm{O}$ & $\mathrm{MgO}$ & $\mathrm{P}_{2} \mathrm{O}_{5}$ & $\mathrm{CaO}$ & $\mathrm{Al}_{2} \mathrm{O}_{3}$ & $\mathrm{MnO}$ & $\mathrm{Na}_{2} \mathrm{O}$ & $\mathrm{Fe}_{2} \mathrm{O}_{3}$ \\
\hline$(\%)$ & 92.4850 & 2.3249 & 2.5057 & 1.0010 & 0.2852 & 0.3287 & 0.1033 & 0.0685 & 0.0903 & 0.0593 \\
\hline
\end{tabular}

selectivity of the agents for metal ions adsorption. These characteristics render these solids as ideal heavy metal adsorbents $[9,10]$. For instance, the maximum adsorption capacity of modified MCM-41 for $\mathrm{Ni}(\mathrm{II}), \mathrm{Cd}(\mathrm{II})$, and $\mathrm{Pb}(\mathrm{II})$ was found to be $12.36,18.25$, and $57.74 \mathrm{mg} / \mathrm{g}$, respectively [11]. It was larger than the capacity of activated carbon. Unfortunately, the main disadvantage of mesoporous material is the lack of popular prices in the process of synthesis, because the price of silica resource is very expensive.

Silica fume is formed as a byproduct during the production of alusil alloy or metallurgy grade silicon. As an industrial solid waste, SF is normally utilized as a substitute for fine aggregates in cement and concrete, in bricks and ceramic tiles and a filler in plastics and paints [12-14]. However, it has pozzolanic properties and phase minerals comprising major silica components (95.1\%) in the amorphous form, with traces of alumina, alkaline metal oxides, and transition metal oxides $[15,16]$. Hence, SF has the capability to become a kind of useful silica resources in the synthesis of mesoporous materials. With the addition of an external silicon source (silica fume) to the synthesis mixture which allows controlling the final $\mathrm{Si} / \mathrm{Al}$ ratio Habib et al. synthesized the ZSM-5 successfully [17]. Recently, with the industrial silica fume as silica source, the MCM-41 and MCM-48 were synthesized $[15,18]$. They proved that the possibility of the mesoporous material can be synthesized by using silica fume as silica source. However, the adsorption capacities of this material are rare for scholar to mention.

This work describes $\mathrm{Cr}(\mathrm{VI})$ removal from aqueous by adsorption on amine-functionalized mesoporous silica prepared from silica fume. The $\mathrm{NH}_{2}-\mathrm{MCM}-41$ grafted with aminopropyls was selected. The $\mathrm{Cr}_{2} \mathrm{O}_{7}{ }^{2-}$ is expected to adsorb on $\mathrm{NH}_{2}-\mathrm{MCM}-41$ at low $\mathrm{pH}$. The adsorption kinetics and equilibrium studies were then conducted to evaluate their adsorption behaviors. The effect of solution $\mathrm{pH}$ was investigated. This study is to provide a better understanding on the adsorption mechanisms of metal ions by $\mathrm{NH}_{2}-\mathrm{MCM}-41$ and a way of mesoporous material synthesis in a popular price.

\section{Experimental}

2.1. Chemicals. Silica fumes (SF) were collected from a local metallurgy-grade silicon factory using an electroprecipitator, and it was used as silica source (Table 1). Surfactant cetyltrimethylammonium bromide (CTAB) was employed as structure directing agent. The organoalkoxysilanes selected for the functionalization process was 3aminopropyl trimethoxysilane (MPTS, Alfa Aesar). Source of metal for sorption experiments was potassium dichromate and sodium hydroxide $(\mathrm{NaOH})$ was obtained from Shanghai Chemical Co. All chemical reagents and solvents were analytical grade and used without further purification.
2.2. Adsorbents Synthesis. In a typical synthesis procedure, mesoporous silica materials were synthesized by using cetyltrimethylammonium bromide (CTAB) as the template and silica fume (SF) as the silica source with the molar ratio of $1.0 \mathrm{SiO}_{2}: 0.3 \mathrm{NaOH}: 0.15 \mathrm{CTAB}: 168 \mathrm{H}_{2} \mathrm{O}$. Exactly $1.33 \mathrm{~g}$ of silica fume and $1.21 \mathrm{~g}$ of CTAB were dissolved at room temperature and stirred for $2 \mathrm{~h}$. The mixtures were then transferred into a flask and heated to $363 \mathrm{~K}$ for $48 \mathrm{~h}$ for hydrothermal reaction. The gray powders were recovered by filtration and extensively washed with deionized water. The samples were dried at $373 \mathrm{~K}$ for $12 \mathrm{~h}$ and then calcined at $823 \mathrm{~K}$ for $5 \mathrm{~h}$ to yield the mesoporous silica materials (MCM-41).

The MCM-41 adsorbent containing aminopropyls, $\mathrm{NH}_{2}$ MCM-41, was prepared by refluxing of $2.5 \mathrm{~g}$ MCM-41 powder in $250 \mathrm{~mL}$ dry toluene (>99.5\%, Mallinckrodt) containing 0.4 M 3-aminopropyltrimethoxysilane (97\%, Aldrich) for $18 \mathrm{~h}$. The $\mathrm{NH}_{2}-\mathrm{MCM}-41$ powder was filtered, washed with toluene, and dried in an oven at $383 \mathrm{~K}$ overnight (toluene purified). The dried adsorbent was ground and sieved to obtain a free flowing powder.

2.3. Characterization. The contents of silica fume were quantified by XRF spectrometer (Rigaku ZSX100). The X-ray powder diffraction spectra were recorded by XRD diffractometer (Rigaku D/MAX-3B) equipped with a liquid nitrogen-cooled germanium solid-state detector using $\mathrm{Cu}-\mathrm{K} \alpha$ radiation over a range of $0.5-8^{\circ}$ with a voltage of $40 \mathrm{kV}$. Nitrogen adsorptiondesorption isotherms were measured at $-196^{\circ} \mathrm{C}$ using a surface area and pore size analyzer (Quantachrome Instruments NOVA 2200e) in order to determine the textural properties. Approximately $0.1 \mathrm{~g}$ of all samples was degassed at $100^{\circ} \mathrm{C}$ for $3 \mathrm{~h}$ under argon gas flow before analysis. The specific surface area was evaluated using the Brunauer-Emmett-Teller (BET) method, and the pore size distribution was calculated from desorption branches of nitrogen isotherms applying the Barrett-Joyner-Halenda (BJH) method. Fourier transform infrared spectra (FTIR) were recorded (Varian 640-IR FTIR) in the range of $400-4000 \mathrm{~cm}^{-1}$ with a resolution of $4 \mathrm{~cm}^{-1}$. The morphology of the mesoporous materials was obtained by electron scanning microscopy (Philips XL-30ESEM-TMP) and transmission electron microcopy (JEOL JEM-2100). The XPS spectra were recorded with a monochromatized $\mathrm{Mg}$ $(\mathrm{K} \alpha)$ source of $1253.6 \mathrm{eV}$ energy. The binding energy scale for final calibration was corrected by the $\mathrm{C} 1 \mathrm{~s}$ peak of $284.6 \mathrm{eV}$ (PHI 5500). Concentrations of Cr(VI) ions were analyzed by a Flame Atomic Absorption Spectrophotometer (AAS, Hitachi Z200).

2.4. Adsorption Experiments. The adsorption experiments were carried out under ambient conditions $\left(25^{\circ} \mathrm{C}\right)$. Analytical grade lead nitrate was used to prepare a stock solution $\mathrm{Cr}(\mathrm{VI})$ of $1000 \mathrm{mg} / \mathrm{L}$, which was further diluted with deionized water to different concentrations for the adsorption experiments. 
In the adsorption kinetics experiments, $\mathrm{NH}_{2}-\mathrm{MCM}-41$ were mixed with $40 \mathrm{mg} / \mathrm{L}$ of $\mathrm{Cr}(\mathrm{VI})$ in $100 \mathrm{~mL}$ solution and stirred with a magnetic stirrer at $200 \mathrm{rpm}$. The kinetic sorption data (discussed in Section 3.2) suggested that $24 \mathrm{~h}$ were sufficient to reach the state of equilibrium. The adsorption isotherm studies were conducted with initial $\mathrm{Cr}(\mathrm{VI})$ concentrations ranging from 5 to $200 \mathrm{mg} / \mathrm{L}$ together with $20 \mathrm{mg} \mathrm{NH}_{2}-\mathrm{MCM}$ $41 \mathrm{in} 100 \mathrm{~mL}$ solution. The initial solution was adjusted by using $\mathrm{HNO}_{3}$ or $\mathrm{NaOH}$ to reach the desired $\mathrm{pH}$ values. For the purpose of analytical characterizations, the $\mathrm{NH}_{2}-\mathrm{MCM}$ 41 samples were recovered by centrifugation, followed by drying.

\section{Results and Discussion}

3.1. Characterization of the MCM-41 and $\mathrm{NH}_{2}-\mathrm{MCM}-41$. Nitrogen adsorption-desorption isotherms obtained at $77 \mathrm{~K}$ of pure. The nitrogen adsorption-desorption isotherms and pore size distributions of the MCM-41 sample are plotted in Figure 1(a). The BJH pore size distribution of MCM-41 shows a relatively narrow distribution with a pronounced peak that corresponds to pores with diameter $2-4 \mathrm{~nm}$. The figure shows the isotherm which is a typical type-IV isotherm with a welldefined hysteresis loop indicating the presence of mesopores. This is an expected result, reflecting that the MCM- 41 surface was indeed.

XRD patterns of two samples are presented in Figure 1(c). An intense peak (100) could be observed for all samples and two well-resolved small peaks (110) and (200) could be observed for MCM-41, being indicative of well-ordered hexagonal mesoporous structures [19]. This result indicates that the mesoporous structure was not destroyed during the surface amino-functionalization process.

Figure 1(b) shows the photographs of MCM- 41 taken with the TEM images. The hexagonal structure can be seen at the sample, indicating that the MCM-41 was successfully synthesized. To better understand the structural and morphological differences between MCM- 41 and $\mathrm{NH}_{2}-\mathrm{MCM}-41$, SEM analysis showed that the $\mathrm{NH}_{2}-\mathrm{MCM}-41$ clearly displays the hexagonal structure. Figure $1(\mathrm{~d})$ shows the representative SEM images of $\mathrm{NH}_{2}-\mathrm{MCM}-41$. At the same time, this hexagonal structure did not disappear with small group of ion from silica fume added to MCM-41. The SEM and TEM images are in accordance with the XRD results in explaining the hexagonal structure in $\mathrm{NH}_{2}-\mathrm{MCM}-41$.

The inner assembly details of MCM- 41 and $\mathrm{NH}_{2}-\mathrm{MCM}$ 41 were illustrated by FTIR spectroscopy. Figure 2 showed the FTIR spectra of unmodified MCM-41 and $\mathrm{NH}_{2}-\mathrm{MCM}-$ 41. The typical vibration modes of MCM- $41\left(\mathrm{OH}, 3432 \mathrm{~cm}^{-1}\right.$; $\mathrm{Si}-\mathrm{O}-\mathrm{Si}, 1090$ and $798 \mathrm{~cm}^{-1}$; $\mathrm{Si}-\mathrm{OH}, 972 \mathrm{~cm}^{-1}$; and $\mathrm{Si}-\mathrm{O}$, $468 \mathrm{~cm}^{-1}$ ) were presented. Comparing the intensity of the unmodified MCM-41, the intensity of the $\mathrm{Si}-\mathrm{OH}$ vibration at $972 \mathrm{~cm}^{-1}$ in $\mathrm{NH}_{2}-\mathrm{MCM}-41$ decreased, which indicated that most of the $\mathrm{Si}-\mathrm{OH}$ bonds on the inner surface of MCM41 had been occupied due to the modification. In addition, the bands at 3432 and $1547 \mathrm{~cm}^{-1}$ in the spectrum implied the existence of the $\mathrm{N}-\mathrm{H}$ stretching and bending vibrations after the modification. Both symmetric and asymmetric $\mathrm{CH}_{2}$
$\left(\operatorname{tas}\left(\mathrm{CH}_{2}\right)=2927 \mathrm{~cm}^{-1}\right.$, ts $\left.\left(\mathrm{CH}_{2}\right)=2856 \mathrm{~cm}^{-1}\right)$ groups [20] were identified. As a result, it indicated that aminopropyl groups had been grafted onto the inner surface of MCM41 via reactions between APTES and $\mathrm{OH}$ groups on the channel wall. From the characterizations we can infer that the interaction mechanism between the silanol groups and the APTES was as follows:

$$
\begin{aligned}
& \mathrm{Si}-\mathrm{OH}+\mathrm{H}_{2} \mathrm{NCH}_{2} \mathrm{CH}_{2} \mathrm{CH}_{2} \mathrm{Si}\left(\mathrm{OC}_{2} \mathrm{H}_{5}\right)_{3} \\
& \quad \longrightarrow \mathrm{Si}-\mathrm{O}-\mathrm{Si}\left(\mathrm{OC}_{2} \mathrm{H}_{5}\right)_{2} \mathrm{CH}_{2} \mathrm{CH}_{2} \mathrm{CH}_{2} \mathrm{NH}_{2}
\end{aligned}
$$

This was also the reason why the two well-resolved small peaks (110) and (200) were absent in amino-functionalised MCM-41 (Figure 1(c)).

As has been reported, in supported $\mathrm{Cr} / \mathrm{SiO}_{2}$ materials chromium ions exist in different oxidation states, which are responsible of their catalytic behavior. XPS is an useful technique to determine the surface of materials. Figure 3(a) shows the XPS spectra of $\mathrm{NH}_{2}-\mathrm{MCM}-41$. The $\mathrm{N}$ 1s spectrum was assigned to peak corresponding to the binding energies of 398.5 and $400.66 \mathrm{eV}$. The $\mathrm{C} 1 \mathrm{~s}$ peak appears at the binding energies corresponding to $208.06 \mathrm{eV}$. The result indicated that amino groups had been grafted onto the inner surface of MCM-41. Figure 3(b) shows that the $-\mathrm{NH}_{3}{ }^{+}$and $-\mathrm{NH}_{2}$ XPS spectra suggest that amino groups exit in the MCM41 and the groups of amino had been changed. As is shown in Figure 2(a), the protonation had occurred on the grafted amino groups. It indicated that the capacity of $\mathrm{NH}_{2}-\mathrm{MCM}-41$ combination with $\mathrm{Cr}_{2} \mathrm{O}_{7}{ }^{2-}$ in the adsorption process is easier.

Figure 3(c) shows the XPS spectra of $\mathrm{NH}_{2}-\mathrm{MCM}-41$ after adsorption. Figure 3(d) illustrates the Cr 2p XPS spectra of the difference in sample. The spectra were deconvoluted using Gaussian functions in order to fit them with the experimental spectra in the $570-595 \mathrm{eV}$ range of binding energy. The significant binding energies at $577.96 \mathrm{eV}$ and $587.66 \mathrm{eV}$ could be attributed to $\mathrm{Cr}$ (III) corresponding to $2 \mathrm{p} 3 / 2$ and $2 \mathrm{p} 1 / 2$ orbitals, respectively. The $\mathrm{Cr} 2 \mathrm{p}$ core region corresponds to the blinding 577.96 and $587.66 \mathrm{eV}$ and the chrome content was $1.94 \%$ indicated that the absorbent had a good adsorb capacity of $\mathrm{Cr}(\mathrm{VI})$. It is known that XPS detections limited by the mean photoelectron escape depth to about $2 \mathrm{~nm}$. Consequently, high mesoporous materials only exhibit a very low surface to the XPS beam [21]. So the low intensity of $\mathrm{Cr}$ $2 p$ signal observed in Figure 3(c) suggests that most of the chromium is on the inner surface hidden into the pores and not detected for the XPS technique.

Figure 3(e) illustrates the $\mathrm{N}$ 1s spectra of $\mathrm{NH}_{2}-\mathrm{MCM}$ 41 after adsorption. The intensity of $-\mathrm{NH}_{3}{ }^{+}$decreased and the peak to the binding energies of 398.5 disappeared. In addition, the peak at $398.8 \mathrm{eV}$ and $401.4 \mathrm{eV}$ before adsorption for $\mathrm{NH}_{2}-\mathrm{MCM}-41$ was different from the peak at $399 \mathrm{eV}$ and $400.7 \mathrm{eV}$ after adsorption, indicating that the structure of $-\mathrm{NH}_{3}{ }^{+}$was changed. The similar phenomenon was observed in the image of $\mathrm{Cr}(\mathrm{VI})$. The result indicated that $-\mathrm{NH}_{3}{ }^{+}$ and $\mathrm{Cr}_{2} \mathrm{O}_{7}{ }^{2-}$ in the process of adsorption are held together by their mutual electrostatic attraction. But the mechanism cannot be described by only one pattern. Another mechanism can be described by another way. Due to the less electron of $\mathrm{Cr}(\mathrm{VI})$ in $\mathrm{Cr}_{2} \mathrm{O}_{7}{ }^{2-}$ and the didymous electron of $-\mathrm{NH}_{3}{ }^{+}$, 


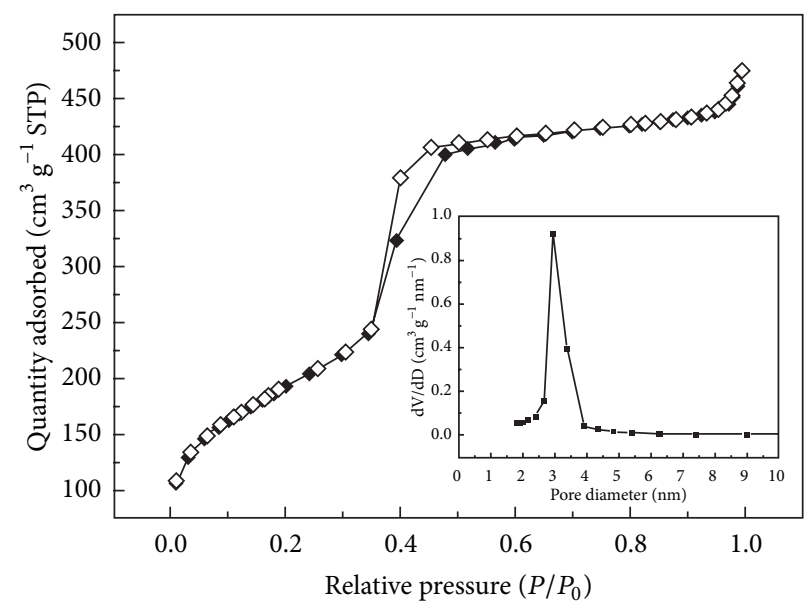

(a)

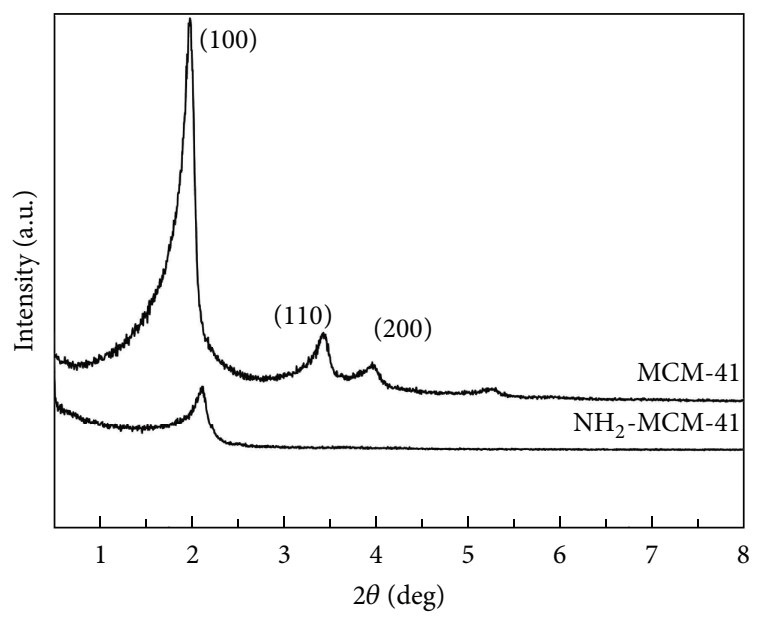

(c)

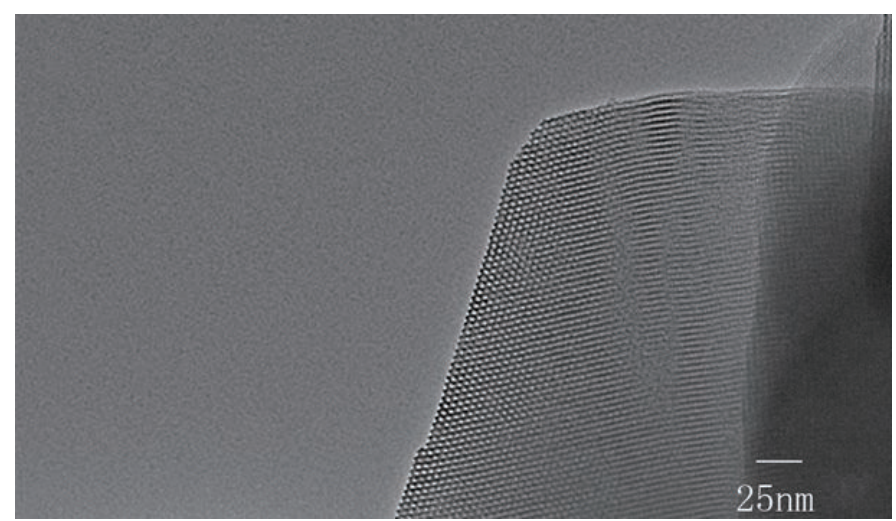

(b)

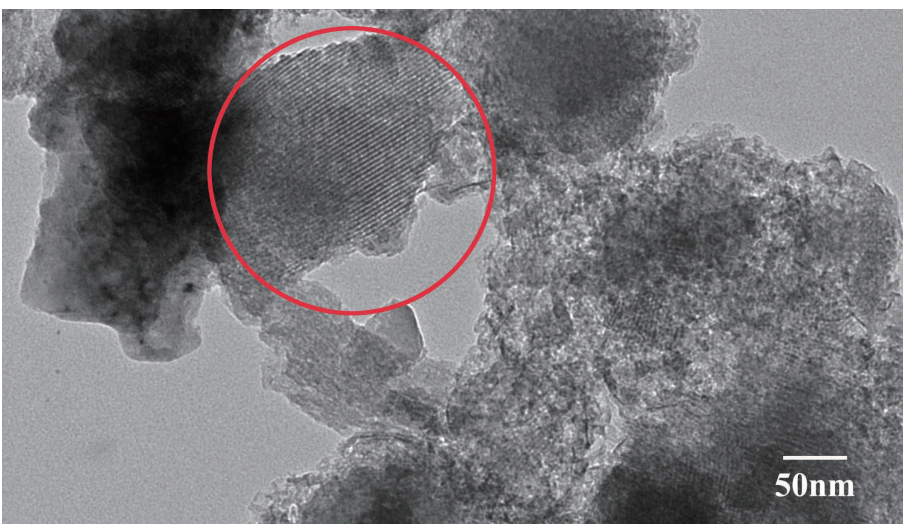

(d)

FIGURE 1: (a) Nitrogen adsorption isotherm of MCM-41. (b) TEM image of the MCM-41. (c) XRD patterns of the MCM-41 and NH - -MCM-41. (d) SEM image of $\mathrm{NH}_{2}-\mathrm{MCM}-4$.

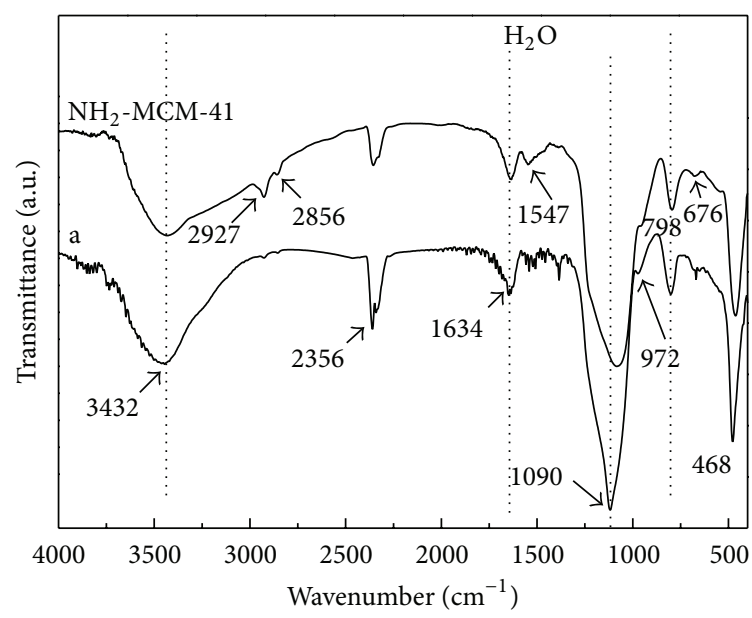

FIGURE 2: FTIR spectra of MCM-41 and $\mathrm{NH}_{2}-\mathrm{MCM}-41$.
$\mathrm{Cr}(\mathrm{VI})$ reached electron from the $-\mathrm{NH}_{3}{ }^{+}$. By sharing a pair of electrons they formed a kind of coordinate bond. But in this research the second mechanism was the dominant.

\section{2. $\mathrm{Cr}(\mathrm{VI})$ Adsorption onto $\mathrm{NH}_{2}-\mathrm{MCM}-41$}

3.2.1. Effect of Initial $p H$ on the Adsorption of $\mathrm{Cr}(V I)$. The $\mathrm{pH}$ value of the system controls the adsorption capacity due to its influence on the charge density of the adsorbent and the ionic forms of the chrome ions in solutions. Hence, the $\mathrm{pH}$ value is one of the most important parameters while assessing the adsorption capacity of an adsorbent for metal ions sequestering from aqueous solution. In the present work, adsorption of $\mathrm{Cr}(\mathrm{VI})$ on the as-prepared $\mathrm{NH}_{2}-\mathrm{MCM}-41$ sample was studied over the initial $\mathrm{Cr}(\mathrm{VI})$ concentration used in the solution which was $40 \mathrm{mg} / \mathrm{L}$. Figure 4 shows the effect of $\mathrm{pH}$ on the adsorption of $\mathrm{Cr}(\mathrm{VI})$ ions where the adsorption 


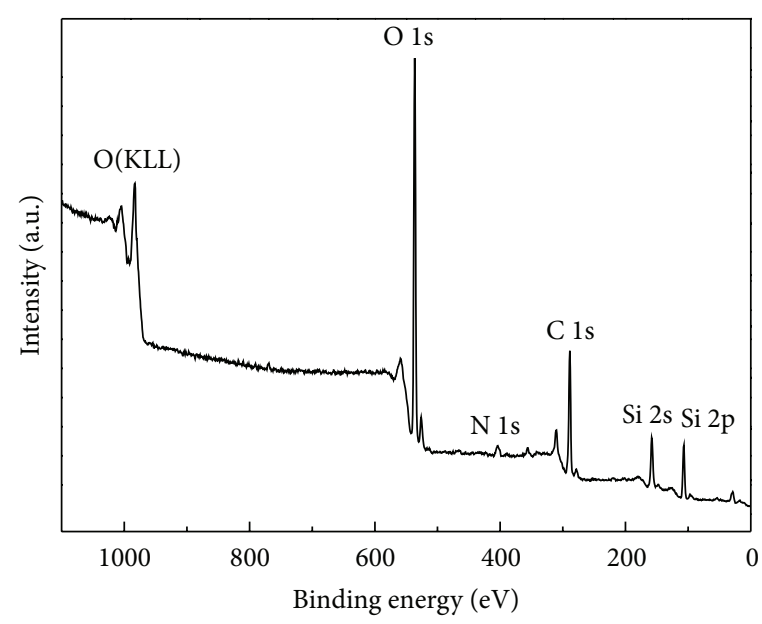

(a)

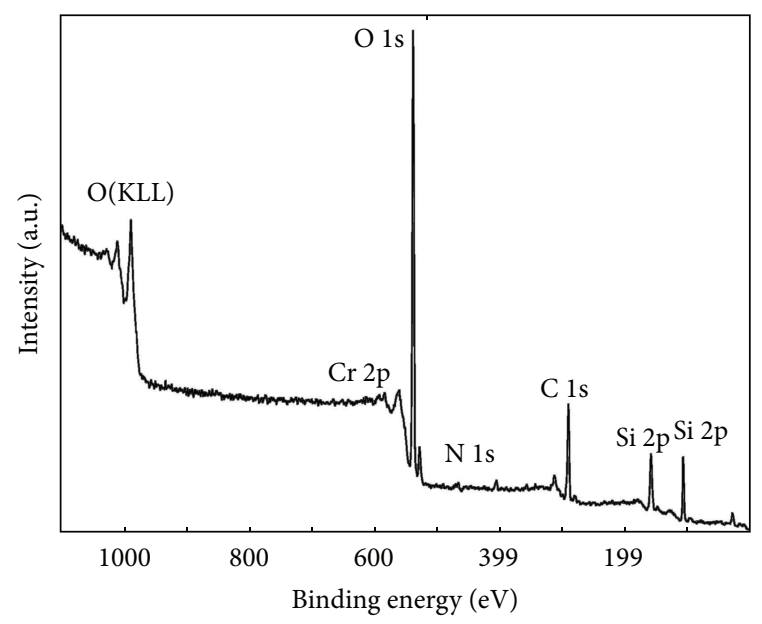

(c)

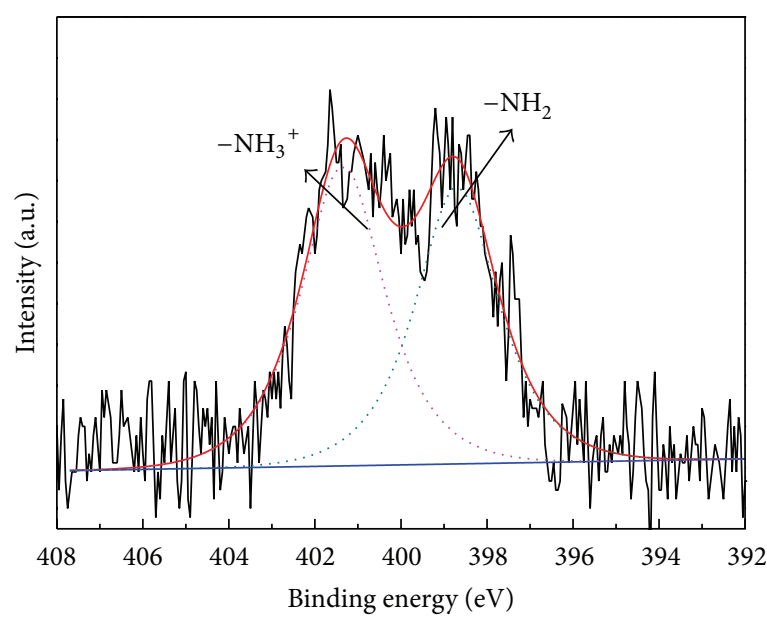

(b)

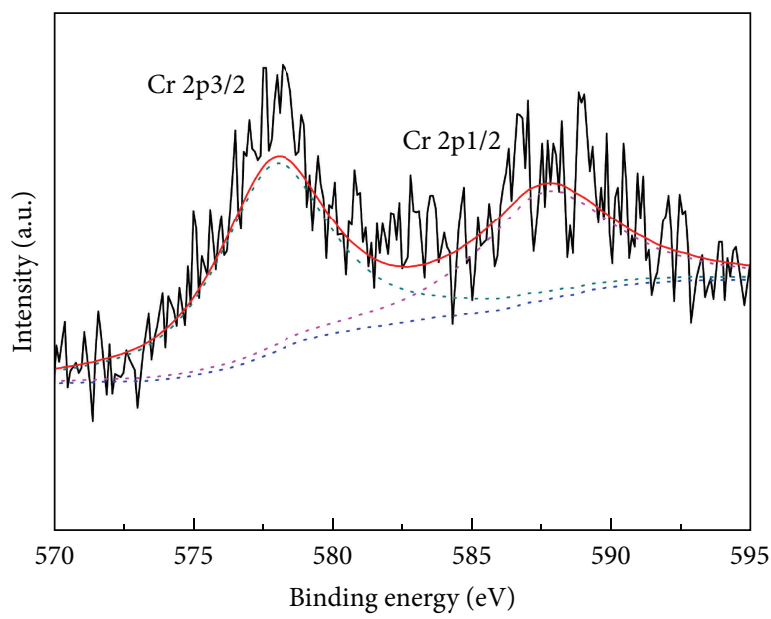

(d)

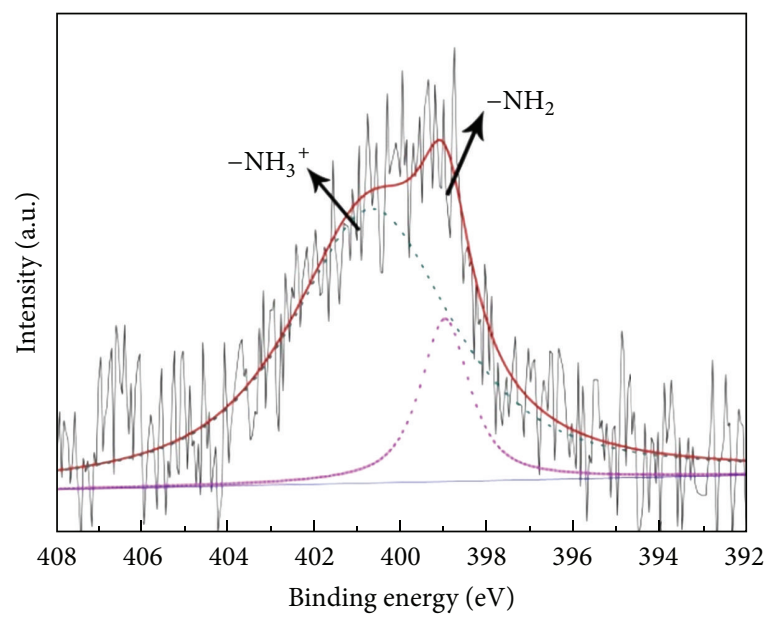

(e)

Figure 3: XPS spectra of $\mathrm{NH}_{2}-\mathrm{MCM}-41$ and Cr-NH$-\mathrm{MCM}-41$. (a) Over all spectra of $\mathrm{NH}_{2}-\mathrm{MCM}-41$; (b) $\mathrm{N}$ 1s spectra of NH$-\mathrm{NCM}_{2}-41$ before adsorption; (c) overall spectra of Cr- $\mathrm{NH}_{2}-\mathrm{MCM}-41$; (d) $\mathrm{Cr} 2 \mathrm{p}$ spectra of Cr- $\mathrm{NH}_{2}-\mathrm{MCM}-41$; (e) N 1s spectra of $\mathrm{NH}_{2}-\mathrm{MCM}-41$ after adsorption. 


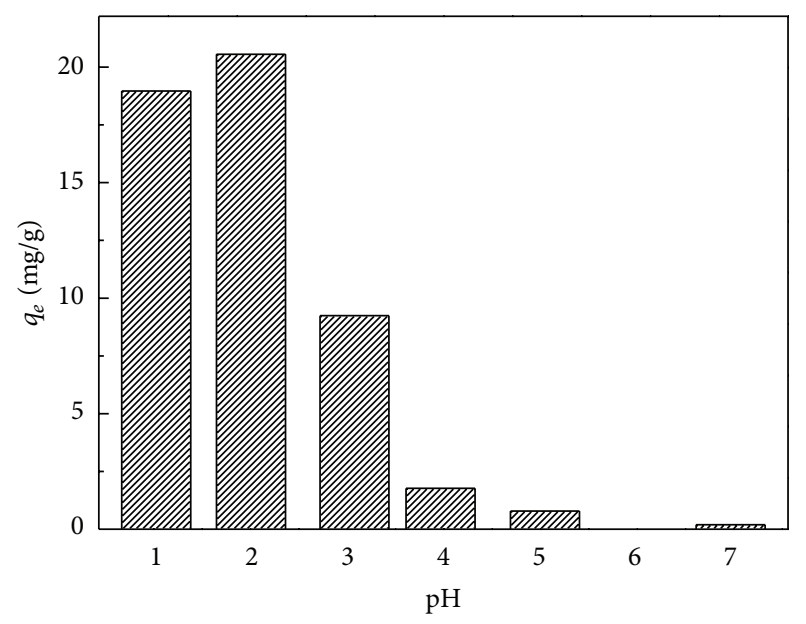

Figure 4: Effect of initial $\mathrm{pH}$ on the adsorption of $\mathrm{Cr}(\mathrm{VI})$.

capacity of $\mathrm{Cr}(\mathrm{VI})$ decreases with the increasing $\mathrm{pH}$ value in the solution and the maximum adsorption capacity of $\mathrm{Cr}(\mathrm{VI})$ was reached at a $\mathrm{pH}$ value of around 2.0 (more than $20 \mathrm{mg} / \mathrm{g}$ ). When the $\mathrm{pH}$ value around 6-7 the adsorption capacity of $\mathrm{Cr}(\mathrm{VI})$ was almost zero. In such a system, active sites are becoming protonated to the virtual appeal to metal binding on the $\mathrm{NH}_{2}-\mathrm{MCM}-41$ surface. This means that at lower $\mathrm{pH}$ the $\mathrm{NH}_{2}-\mathrm{MCM}-41$ surface becomes more positively charged thus producing the attraction between the surface and $\mathrm{Cr}_{2} \mathrm{O}_{7}{ }^{2-}$. At $\mathrm{pH}=2$, there are many species of chromium ions in solution such as $\mathrm{CrO}_{4}{ }^{2-}, \mathrm{HCrO}_{4}{ }^{-}$, and $\mathrm{H}_{2} \mathrm{Cr}_{2} \mathrm{O}_{7}$. But the predominant species is $\mathrm{HCrO}_{4}{ }^{-}$. However, the adsorption capacity decreased at $\mathrm{pH}<1$, which was related to the formation of nonionic $\mathrm{H}_{2} \mathrm{Cr}_{2} \mathrm{O}_{7}$ [22]. As the $\mathrm{pH}$ value increases, less positively charged surface becomes available thus controlling greater metal uptake. Therefore, the $\mathrm{pH}$ value of 2.0 was selected to be the optimum $\mathrm{pH}$ value for further studies. In order to maintain the $\mathrm{pH}$, the initial solution was adjusted by using $\mathrm{HNO}_{3}$ or $\mathrm{NaOH}$ to reach the $\mathrm{pH}$ values.

3.2.2. Adsorption Kinetics. Adsorption kinetics was one of the most important characters which represented the adsorption efficiency. The effect of different contact time intervals ranging from 0 to $720 \mathrm{~min}$ on the adsorption of $\mathrm{Cr}(\mathrm{VI})$ by $\mathrm{NH}_{2}$ MCM-41 was shown in Figure 5. It could be observed that in the process of the absorption of $\mathrm{Cr}(\mathrm{VI})$ by $\mathrm{NH}_{2}-\mathrm{MCM}-41$ within 240 min was fast, relatively. The absorption of $\mathrm{Cr}(\mathrm{VI})$ by $\mathrm{NH}_{2}-\mathrm{MCM}-41$ approached an adsorption equilibrium within $600 \mathrm{~min}$ with the removal rate and adsorption capacity reaching $91.8 \%$ and $45.89 \mathrm{mg} / \mathrm{g}$. The high initial removal rate and the equilibration time demonstrated that the surface of the modified MCM-41 had density of active sites. The possible reasons were that postgrafting could not break the mesoporous structure and functional groups were distributed in the pipe, and the adsorption of $\mathrm{Cr}(\mathrm{VI})$ onto the $\mathrm{NH}_{2}$ MCM-41 support proceeded with the intended $\mathrm{Cr}-\mathrm{NH}_{2}$ MCM-41 chelate format [23].

The kinetics on the $\mathrm{NH}_{2}-\mathrm{MCM}-41$ is described by the pseudo-first-order and pseudo-second-order models and the

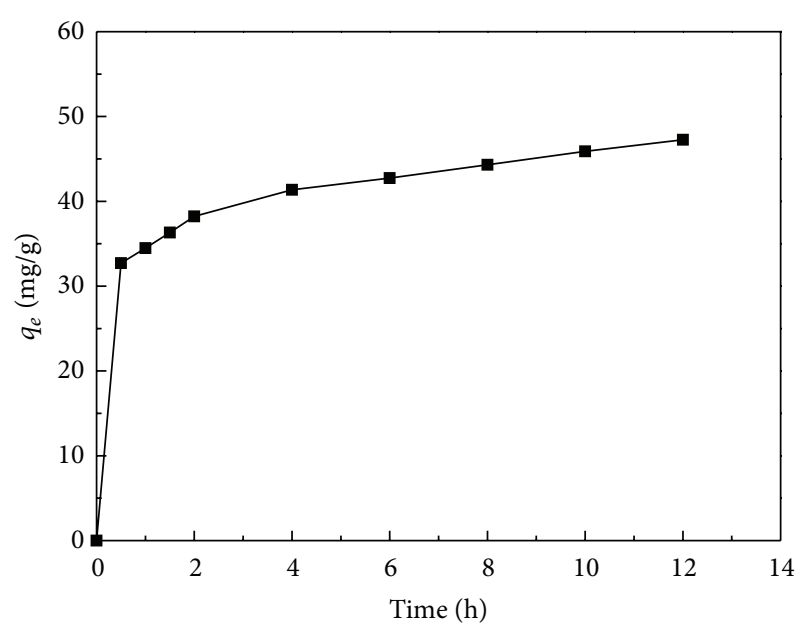

FIgURE 5: The Cr(VI) adsorption capacity and removal efficiency as functions with contact time (solution volume $100 \mathrm{~mL}$, adsorbent $20 \mathrm{mg}, 200 \mathrm{rpm}, 25^{\circ} \mathrm{C}$, initial $\mathrm{Cr}(\mathrm{VI})$ concentration $40 \mathrm{mg} / \mathrm{L}$ ).

intraparticle diffusion model. The pseudo-first-order model is generally expressed as follows:

$$
\ln \left(q_{e}-q\right)=\ln q_{e}-k_{1} t
$$

where $q_{e}$ and $q$ are the sorption capacities at equilibrium and time, respectively $(\mathrm{mg} / \mathrm{g}) . k_{1}$ represents the rate constant of the pseudo-first-order kinetic model $\left(\mathrm{min}^{-1}\right)$. The pseudosecond-order model equation is given as follows:

$$
\frac{t}{q}=\frac{t}{q_{e}}+\frac{1}{k_{2} q_{e}^{2}},
$$

where $k_{2}$ is the rate constant of the pseudo-second-order kinetic model (g/mg min). The intraparticle diffusion model equation is given as

$$
q_{t}=k_{\mathrm{ip}} t^{1 / 2}+C
$$

where $k_{\text {ip }}$ is the rate constant of the intraparticle diffusion $\left(\mathrm{mg} \cdot \mathrm{g}^{-1} \cdot \mathrm{min}^{-1 / 2}\right)[24]$.

The adsorption kinetics of $\mathrm{Cr}(\mathrm{VI})$ by $\mathrm{NH}_{2}-\mathrm{MCM}-41$ was investigated at $\mathrm{pH}=2$. The good accessibility of the chelating sites grafted on the $\mathrm{NH}_{2}-\mathrm{MCM}-41$ mesoporous silica matrix is reflected by the kinetics of the interaction between immobilized ligand and the metal ion. The sorption kinetic data were examined by using pseudo-first-order, pseudo-secondorder, and intraparticle diffusion kinetic models (Figure 6). It can be seen from the values of $R^{2}$ that the adsorption process follows the intraparticle diffusion model. Therefore, surface sorption contributes less to the rate limiting step than intraparticle diffusion. Surface, pore, and intraparticle diffusion could be the plausible means that could characterize the adsorption of $\mathrm{Cr}(\mathrm{VI})$ onto the amino-group grafted MCM-41 adsorbent surface. Analysis of the experimental data with the pseudo-second-order and pseudo-first-order kinetic models both showed agreement of the sets of data (Table 2). The results could be reasonably described by 
TABLE 2: Kinetic model parameters for Cr(VI).

\begin{tabular}{lcccr}
\hline Model & $q_{e . \exp }(\mathrm{mg} / \mathrm{g})$ & $k$ & $q_{e . \text { cal }}(\mathrm{mg} / \mathrm{g})$ or C & $R^{2}$ \\
\hline Pseudo-first-order & & 0.059 & 26.87 & 0.957 \\
Pseudo-second-order & 47.27 & 0.04 & 50.00 & 0.998 \\
Intraparticle diffusion & & 5.133 & 29.95 & 0.982 \\
\hline
\end{tabular}

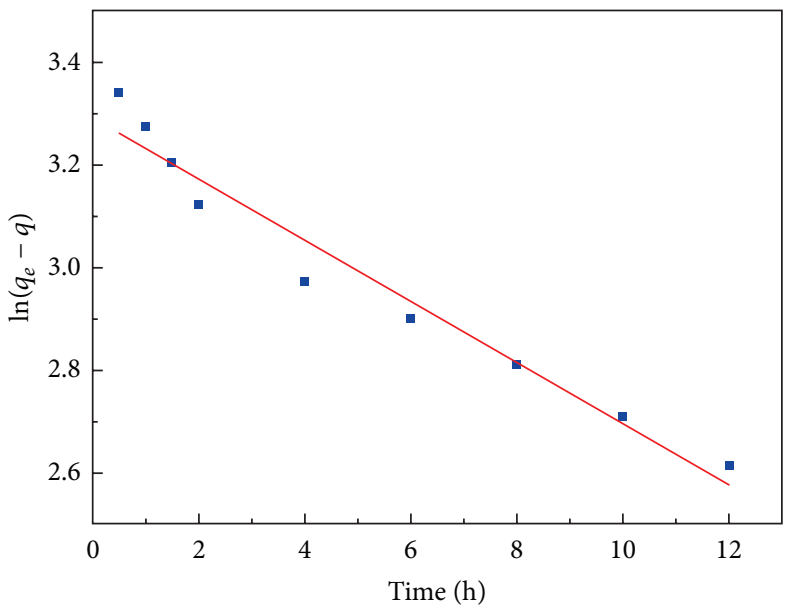

(a)

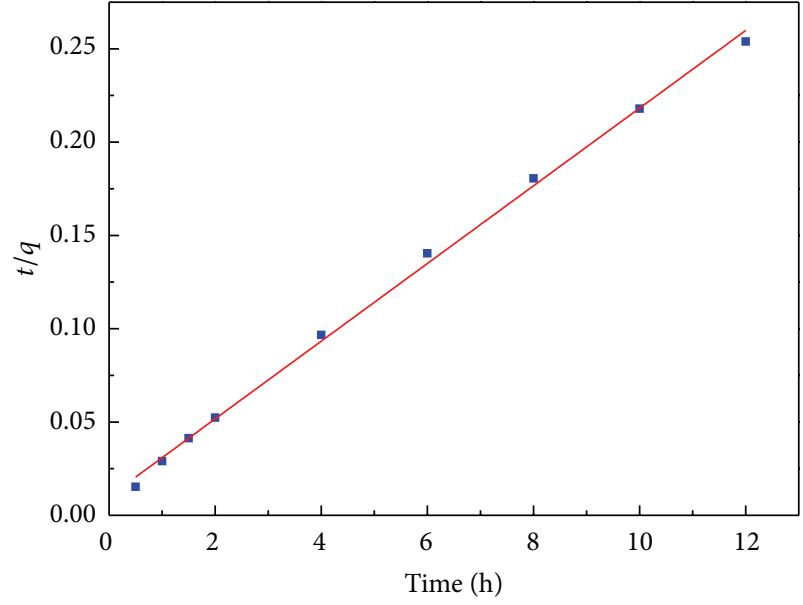

(b)

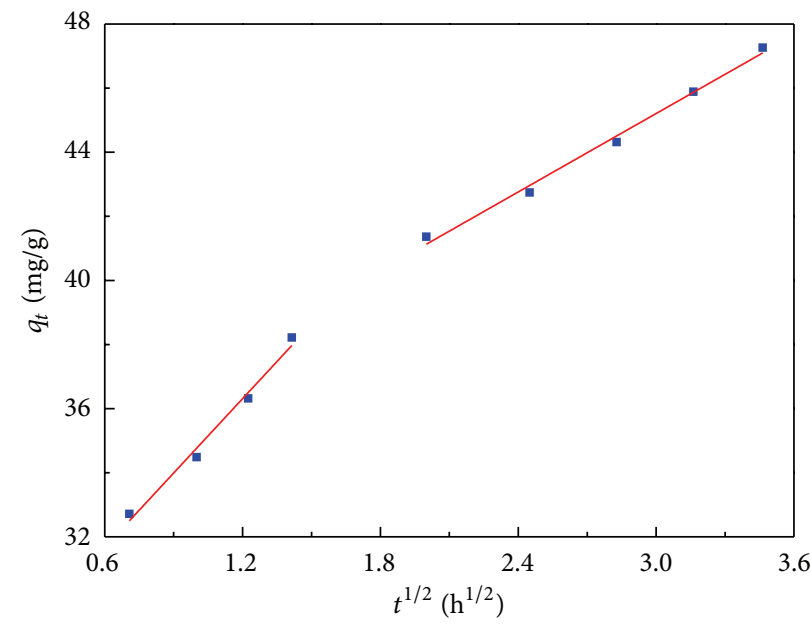

(c)

Figure 6: (a) Pseudo-first-order model fit for the adsorption of $\mathrm{Cr}(\mathrm{VI})$ by $\mathrm{NH}_{2}$-MCM-41. (b) Pseudo-second-order model fit for the adsorption of $\mathrm{Cr}(\mathrm{VI})$ by $\mathrm{NH}_{2}-\mathrm{MCM}-41$. (c) Intraparticle diffusion model fit for the adsorption of $\mathrm{Cr}(\mathrm{VI})$ by $\mathrm{NH}_{2}-\mathrm{MCM}-41$.

pseudo-second-order kinetic model with a high correlation coefficient (Table 2), suggesting an adsorption process of rate limiting step. Additionally, the calculated values of $q_{e . c a l}$ obtained from pseudo-second-order models showed good agreement with the experimental values. It can be inferred that the process was limited by the chemical adsorption [25]. The possible process of adsorption was $\mathrm{Cr}(\mathrm{VI})$ which could combine with the amino structure. In the beginning of the adsorption process $\mathrm{Cr}(\mathrm{VI})$ combined with $-\mathrm{NH}_{2}$ which is outside the MCM-41. With the adsorption process, the
$-\mathrm{NH}_{2}$ outside of the MCM-41 was less and then the rate of adsorption was slow. With the process of intraparticle diffusion, more $\mathrm{Cr}(\mathrm{VI})$ into the MCM-41 and then $\mathrm{Cr}(\mathrm{VI})$ combined with the $-\mathrm{NH}_{2}$ which is inside the MCM-41.

3.2.3. Adsorption Isotherms. The adsorption capacity of $\mathrm{NH}_{2}-$ MCM- $41, q_{e}(\mathrm{mg} / \mathrm{g})$ was plotted as a function of the equilibrium concentrations of $\mathrm{Cr}(\mathrm{VI})$. In order to investigate the adsorption mechanism, the adsorption data were analyzed by using Langmuir and Freundlich adsorption isotherms. 
TABLE 3: Langmuir and Frenudlich isotherm parameters for $\mathrm{Cr}(\mathrm{VI})$ adsorption on $\mathrm{NH}_{2}-\mathrm{MCM}-41$ in different temperature.

\begin{tabular}{|c|c|c|c|c|c|c|}
\hline \multirow{2}{*}{ Model } & \multicolumn{3}{|c|}{ Langmuir } & \multicolumn{3}{|c|}{ Frenudlich } \\
\hline & $q_{m}$ & $b$ & $R^{2}$ & $n_{f}$ & $k_{f}$ & $R^{2}$ \\
\hline $25^{\circ} \mathrm{C}$ & 60.91 & 0.069 & 0.994 & 1.927 & 7.463 & 0.910 \\
\hline $35^{\circ} \mathrm{C}$ & 80.06 & 0.262 & 0.980 & 2.674 & 14.04 & 0.921 \\
\hline $45^{\circ} \mathrm{C}$ & 82.05 & 0.443 & 0.971 & 3.115 & 19.47 & 0.874 \\
\hline
\end{tabular}

The Langmuir and Freundlich equations are the most common models employed to describe the adsorption process in heterogeneous systems. The Langmuir model assumes monolayer adsorption on the solid surface, while Freundlich model is empirical in nature. The Langmuir equation was expressed as

$$
\frac{C_{e}}{q_{e}}=\frac{C_{e}}{q_{m}}+\frac{1}{q_{m} K_{L}}
$$

where $q_{e}(\mathrm{mg} / \mathrm{g})$ is the equilibrated adsorption amount, $C_{e}$ $(\mathrm{mg} / \mathrm{L})$ is the equilibrated concentration of metal ions, $q_{m}$ $(\mathrm{mg} / \mathrm{g})$ is the saturated adsorption capacity of the adsorbent, and $K_{L}$ is the Langmuir constant related to the free energy of adsorption [26]. While the Freundlich isotherm is an empirical equation described multilayer adsorptions and assuming the adsorption surface was heterogeneous, the equation was written as

$$
\log q_{e}=\log K_{F}+\frac{1}{n} \log C_{e}
$$

where $K_{F} \quad(\mathrm{~L} / \mathrm{mg})$ is the Freundlich constant related to the adsorption capacity of the adsorbent and $n$ is the heterogeneity factor indicating the adsorption intensity of the adsorbent [27]. All of the isotherm constants and correlation coefficients computed by nonlinear curve fitting are given in Table 3. Each value in these tables is the mean of three determinations with an accepted relative standard deviation of $\pm 3 \%$.

The results show that the adsorption equilibrium data obeyed the Langmuir model, and the Langmuir model should better describe the adsorption system on $\mathrm{NH}_{2}-\mathrm{MCM}-41$ than the Freundlich model. These results suggested that the adsorption of $\mathrm{Cr}(\mathrm{VI})$ onto $\mathrm{NH}_{2}-\mathrm{MCM}-41$ was monolayer, and $\mathrm{NH}_{2}-\mathrm{MCM}-41$ surface was homogeneous. Calculation of the isotherm parameters using these plots provided the data presented in Table 3. When the aqueous metal concentration increased, the saturation constant value was reached. Figure 7 shows the adsorption isotherms at $25^{\circ} \mathrm{C}, 35^{\circ} \mathrm{C}$, and $45^{\circ} \mathrm{C}$. The adsorption capacity of $\mathrm{NH}_{2}-\mathrm{MCM}-41$ was compared with different temperature. The maximum $\mathrm{Cr}(\mathrm{VI})$ adsorption capacity of $\mathrm{NH}_{2}-\mathrm{MCM}-41$ in $25^{\circ} \mathrm{C}$ amounted to $60.9 \mathrm{mg} / \mathrm{g}$. Whereas the maximum $\mathrm{Cr}(\mathrm{VI})$ adsorption capacity of $\mathrm{NH}_{2}$ MCM-41 in $35^{\circ} \mathrm{C}$ amounted to $80.06 \mathrm{mg} / \mathrm{g}$. On the other hand, the values of $n$ were all greater than 1 for the different temperature, indicative of high adsorption intensity.

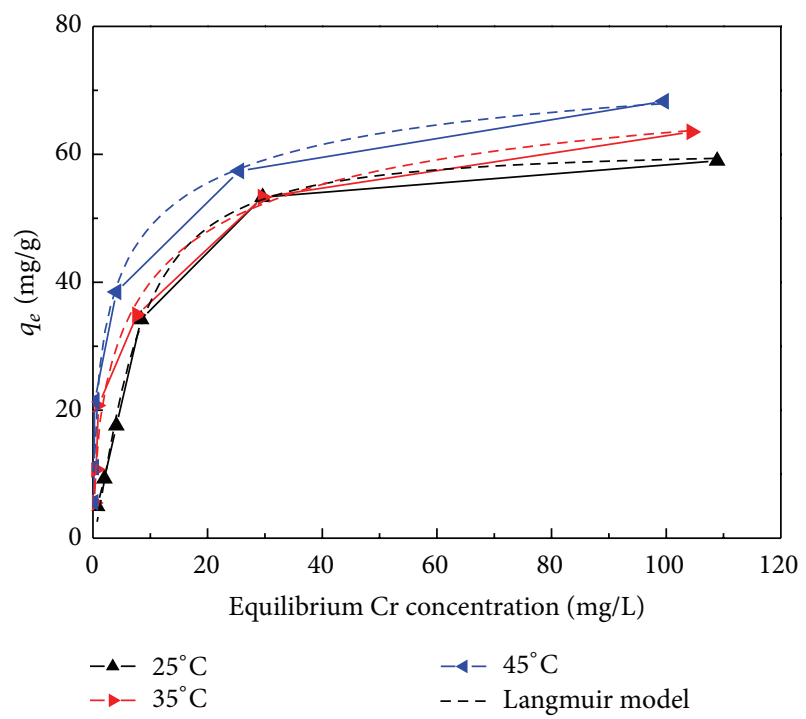

FIgure 7: Adsorption isotherms at $25^{\circ} \mathrm{C}, 35^{\circ} \mathrm{C}$, and $45^{\circ} \mathrm{C}$ of $\mathrm{Cr}(\mathrm{VI})$ on $\mathrm{NH}_{2}$-MCM-41.

Gibbs free energy change $(\Delta G)$, entropy change $(\Delta S)$, equilibrium constant $\left(K_{\mathrm{eq}}\right)$, and enthalpy change $(\Delta H)$ were estimated from the following:

$$
\begin{gathered}
\Delta G=-R T \ln b, \\
\ln b=-\frac{\Delta H}{(R T)}+\frac{\Delta S}{R}, \\
\Delta S=\frac{(\Delta H-\Delta G)}{T}, \\
b=\frac{C_{0}}{C_{e}},
\end{gathered}
$$

where $b$ is the initial concentration of $\mathrm{Cr}(\mathrm{VI})$ removed from $\mathrm{NH}_{2}$-MCM-41 per volume of solution used for this study $\left(C_{0}\right), C_{e}$ is the concentration of $\mathrm{Cr}(\mathrm{VI})$ solution at equilibrium, $T$ is the temperature of solution measured in Kelvin, and $R$ is the universal gas constant $(8.314 \mathrm{~J} /(\mathrm{mol} \cdot \mathrm{K}))$ [28].

Table 4 shows the estimated value of thermodynamic parameters for $\mathrm{NH}_{2}-\mathrm{MCM}-41$. The sign of the Gibbs free energy change value shows that the adsorption process was faster with the increase of temperature, and the sign of the entropy change value also shows that the process follows the increase of entropy. Additionally, the sign of enthalpy 
TABLE 4: Thermodynamic parameter for adsorption of $\mathrm{Cr}(\mathrm{VI})$ at different temperatures on $\mathrm{NH}_{2}-\mathrm{MCM}-41$.

\begin{tabular}{lccc}
\hline$T(K)$ & $\Delta G(\mathrm{~kJ} / \mathrm{mol})$ & $\Delta H(\mathrm{~kJ} / \mathrm{mol})$ & $\Delta S[\mathrm{~J} /(\mathrm{mol} \cdot \mathrm{K})]$ \\
\hline 298 & -1.506 & & \\
308 & -1.665 & 2.024 & 39.876 \\
318 & -1.843 & & \\
\hline
\end{tabular}

change value confirmed the endothermic disposition of the adsorption process.

\section{Conclusion}

Result of characterization of the MCM-41 show that the MCM-41 was successfully synthesized with silica fume (SF) as the silica source. The maximum removal of $\mathrm{Cr}(\mathrm{VI})$ was reached at a $\mathrm{pH}$ value of around 2.0, when the $\mathrm{NH}_{2}-\mathrm{MCM}-41$ is the absorbent. In addition, the kinetics analysis revealed that the overall adsorption process was successfully fitted with the pseudo-second-order kinetic model. The adsorption data for $\mathrm{Cr}(\mathrm{VI})$ had a good fit with Langmuir isotherm and the maximum adsorption capacity of Cr(VI) was $82.05 \mathrm{mg} / \mathrm{g}$ at $45^{\circ} \mathrm{C}$. The intensity of $-\mathrm{NH}_{3}{ }^{+}$in XPS spectra decreased and the peak to the binding energies of 398.5 disappeared indicating that $-\mathrm{NH}_{3}{ }^{+}$and $\mathrm{Cr}_{2} \mathrm{O}_{7}{ }^{2-}$ in the process of adsorption are held together by their mutual electrostatic attraction.

\section{Conflict of Interests}

The authors declare that there is no conflict of interests regarding the publication of this paper.

\section{Acknowledgments}

Financial support from NSFC (21307046), the Personnel Training Foundation of Kunming University of Science and Technology (14118775), and the Foundation of Analysis and Testing of Kunming University of Science and Technology (20140651) was gratefully acknowledged.

\section{References}

[1] Z. Wang, Y. Lin, J. Sun et al., "Adsorption characteristic of modified tea dregs for $\mathrm{Cr}(6+)$ in electroplating wastewater," Journal of Yangzhou University, vol. 3, p. 18, 2011.

[2] D. Yongguang, Y. Hengpeng, L. Guiliang, D. Dongyun, and Z. Liyun, "Study on treatment of chrome wastewater by electrodialysis process," Industrial Safety and Environmental Protection, vol. 1, pp. 35-37, 2011.

[3] M. Lelli, S. Grassi, M. Amadori, and F. Franceschini, "Natural $\mathrm{Cr}(\mathrm{VI})$ contamination of groundwater in the Cecina coastal area and its inner sectors," Environmental Earth Sciences, vol. 71, pp. 3907-3919, 2014.

[4] V. N. Montesinos, N. Quici, and E. B. Halac, "Highly efficient removal of $\mathrm{Cr}(\mathrm{VI})$ from water with nanoparticulated zerovalent iron: understanding the $\mathrm{Fe}(\mathrm{III})-\mathrm{Cr}(\mathrm{III})$ passive outer layer structure," Chemical Engineering Journal, vol. 244, pp. 569-575, 2014.
[5] S. K. Soni, R. Singh, and M. Singh, "Petreatment of Cr(VI)amended soil with chromate-reducing rhizobacteria decreases plant toxicity and increases the yield of Pisum sativum," Archives of Environmental Contamination and Toxicology, vol. 44, pp. 616-627, 2014.

[6] Z. Ai, Y. Cheng, L. Zhang, and J. Qiu, "Efficient removal of $\mathrm{Cr}(\mathrm{VI})$ from aqueous solution with $\mathrm{Fe} @ \mathrm{Fe}_{2} \mathrm{O}_{3}$ core-shell nanowires," Environmental Science \& Technology, vol. 42, no. 18, pp. 6955-6960, 2008.

[7] H. Yang, W. Zhang, and R. Hu, "Removal rate of $\mathrm{Cr}(\mathrm{VI})$ in wastewater onto clinoptololite modified by cetyltrimethylammonium bromide," Journal of the Chinese Ceramic Society, vol. 38, no. 11, pp. 2143-2147, 2010.

[8] K. Peng, Z. Jia, R. Zhu, and J. Zhou, "Adsorption of chromium (VI) onto mesoporous Fe-Mg composite oxide sorbent," Journal of the Chinese Ceramic Society, vol. 39, no. 10, pp. 1651-1658, 2011.

[9] K. Dimos, P. Stathi, M. A. Karakassides, and Y. Deligiannakis, "Synthesis and characterization of hybrid MCM-41 materials for heavy metal adsorption," Microporous and Mesoporous Materials, vol. 126, no. 1-2, pp. 65-71, 2009.

[10] W. Shengju, Z. Bingru, and L. Fengting, "The application of mesoporous adsorbent in heavy metals removal from aqueous solution," Petroleum Processing Section, vol. 7, pp. 134-140, 2009.

[11] A. Heidari, H. Younesi, and Z. Mehraban, "Removal of $\mathrm{Ni}(\mathrm{II}), \mathrm{Cd}(\mathrm{II})$, and $\mathrm{Pb}(\mathrm{II})$ from a ternary aqueous solution by amino functionalized mesoporous and nano mesoporous silica," Chemical Engineering Journal, vol. 153, no. 1-3, pp. 7079, 2009.

[12] Y.-W. Chan and S.-H. Chu, "Effect of silica fume on steel fiber bond characteristics in reactive powder concrete," Cement and Concrete Research, vol. 34, no. 7, pp. 1167-1172, 2004.

[13] R. Siddique, "Utilization of silica fume in concrete: review of hardened properties," Resources, Conservation and Recycling, vol. 55, no. 11, pp. 923-932, 2011.

[14] M. S. Amin and F. S. Hashem, "Hydration characteristics of hydrothermal treated cement kiln dust-sludge-silica fume pastes," Construction and Building Materials, vol. 25, no. 4, pp. 1870-1876, 2011.

[15] W. Zhu, Y. Zhou, W. Ma, M. Li, J. Yu, and K. Xie, "Using silica fume as silica source for synthesizing spherical ordered mesoporous silica," Materials Letters, vol. 92, pp. 129-131, 2013.

[16] W. J. Zhu, M. M. Li, W. H. Ma, J. Yu, and K. Q. Xie, "Effect binary surfactant system on morphologies and structural properties of mesoporous silica materials prepared from silica from silica fume," Integrated Ferroelectrics, vol. 147, pp. 115-122, 2013.

[17] S. Habib, F. Launay, S. Laforge et al., "High catalytic cracking activity of Al-MCM-41 type materials prepared from ZSM-5 zeolite crystals and fumed silica," Applied Catalysis A: General, vol. 344, no. 1-2, pp. 61-69, 2008.

[18] F.-Y. Wei, Z.-W. Liua, J. Lub, and Z.-T. Liu, "Synthesis of mesoporous MCM-48 using fumed silica and mixed surfactants," Microporous and Mesoporous Materials, vol. 131, pp. 224-229, 2010.

[19] Y.-Y. Ma, P.-N. Jia, X.-C. Li, N. Liu, and Y.-L. Ma, "Synthesis of the $\mathrm{ZrO}_{2}-\mathrm{SiO}_{2}$ microspheres as a mesoporous candidate material," Journal of Porous Materials, vol. 19, no. 6, pp. 10471052, 2012.

[20] T. Martin, A. Galarneau, D. Brunel, V. Izard, and V. Hulea, “29O-02 towards total hydrophobisation of MCM-41 type silica surface," Studies in Surface Science and Catalysis, vol. 135, p. 178, 2001. 
[21] S. K. Kumar and C. U. Kumar, "Microwave assisted preparation of n-butylacrylate grafted chitosanand its application for $\mathrm{Cr}(\mathrm{VI})$ adsorption," International Journal of Biological Macromolecules, vol. 66, pp. 135-143, 2014.

[22] G. Niu, W. Liu, T. Wang, and J. Ni, "Absorption of Cr(VI) onto amino-modified titanate nanotubes using 2-Bromoethylamine hydrobromide through SN2 reaction," Journal of Colloid and Interface Science, vol. 401, pp. 133-140, 2013.

[23] J. Huang, M. Ye, Y. Qu et al., "Pb (II) removal from aqueous media by EDTA-modified mesoporous silica SBA-15," Journal of Colloid and Interface Science, vol. 385, no. 1, pp. 137-146, 2012.

[24] R. Xu, M. Jia, Y. Zhang, and F. Li, "Sorption of malachite green on vinyl-modified mesoporous poly(acrylic acid) $/ \mathrm{SiO}_{2}$ composite nanofiber membranes," Microporous and Mesoporous Materials, vol. 149, no. 1, pp. 111-118, 2012.

[25] Y. P. Kumar, P. King, and V. S. R. K. Prasad, "Equilibrium and kinetic studies for the biosorption system of copper(II) ion from aqueous solution using Tectona grandis L.f. leaves powder," Journal of Hazardous Materials, vol. 137, no. 2, pp. 1211-1217, 2006.

[26] K. Wantala, S. Sthiannopkao, B.-O. Srinameb, N. Grisdanurak, K.-W. Kim, and S. Han, "Arsenic adsorption by Fe loaded on RH-MCM-41 synthesized from rice husk silica," Journal of Environmental Engineering, vol. 138, no. 1, pp. 119-128, 2012.

[27] M. V. Lombardo, M. Videla, A. Calvo, F. G. Requejo, and G. J. A. A. Soler-Illia, "Aminopropyl-modified mesoporous silica SBA15 as recovery agents of $\mathrm{Cu}(\mathrm{II})$-sulfate solutions: adsorption efficiency, functional stability and reusability aspects," Journal of Hazardous Materials, vol. 223-224, pp. 53-62, 2012.

[28] P. O. Boamah, Q. Zhang, M. Hua et al., "Lead removal onto cross-linked low molecular weight chitosan pyruvic acid derivatives," Carbohydrate Polymers, vol. 110, pp. 518-527, 2014. 

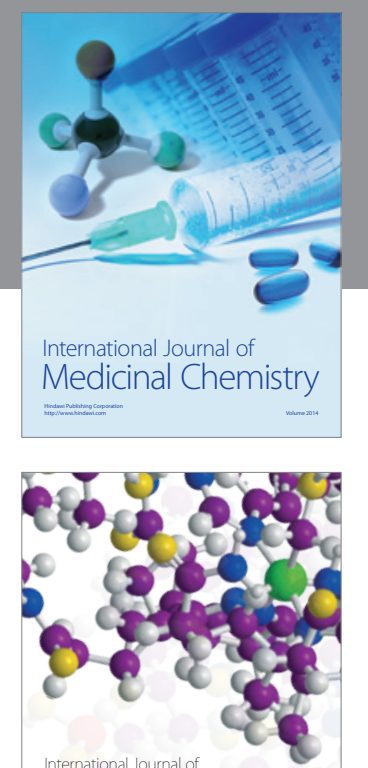

\section{Carbohydrate} Chemistry

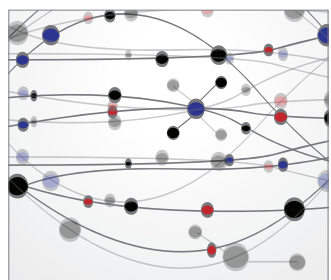

The Scientific World Journal
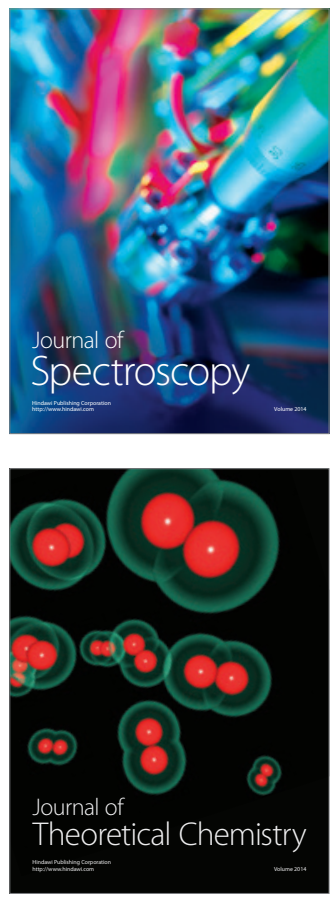
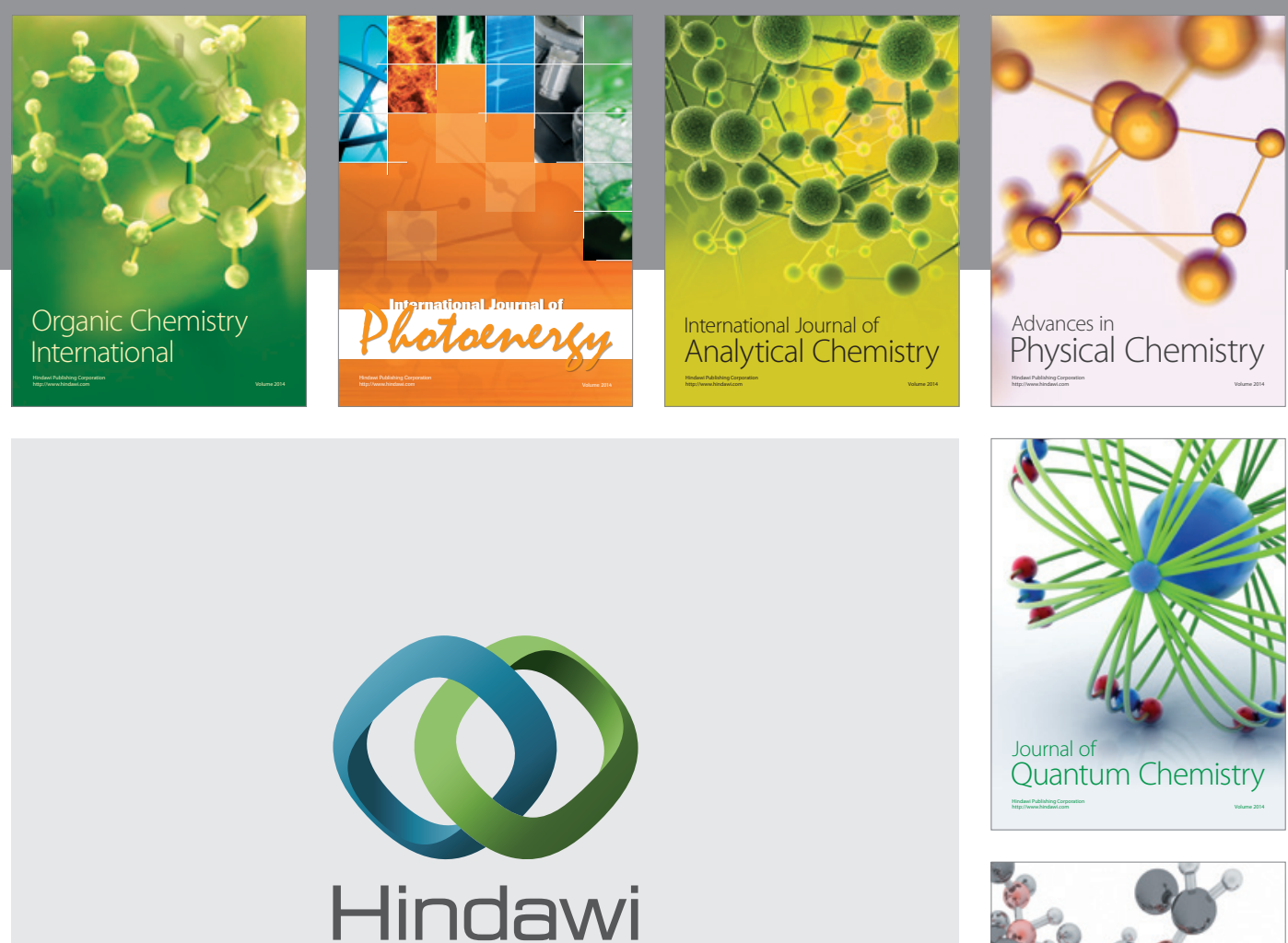

Submit your manuscripts at

http://www.hindawi.com

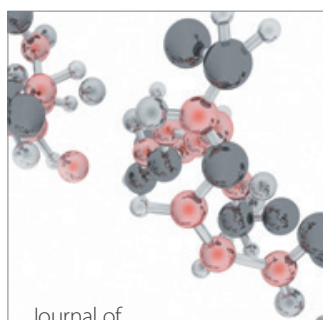

Analytical Methods

in Chemistry

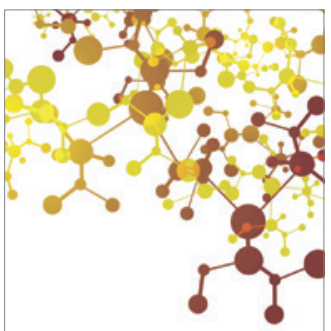

Journal of

Applied Chemistry

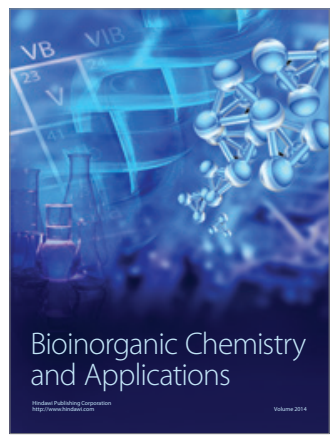

Inorganic Chemistry
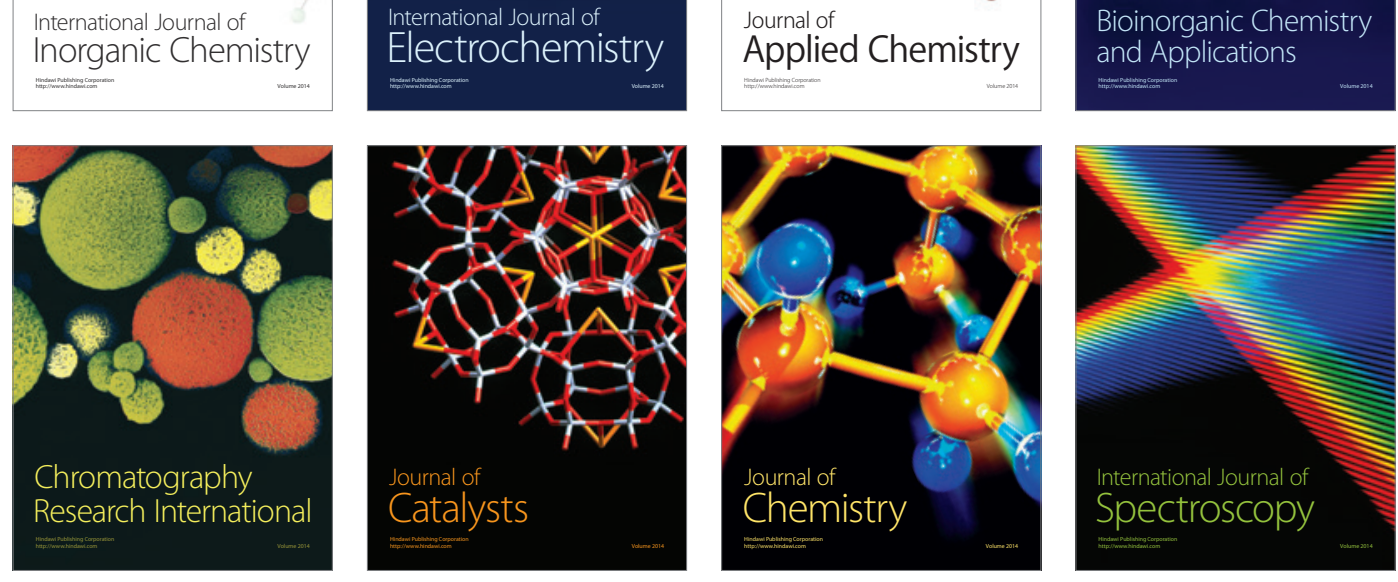